\title{
Arbor
}

\section{Ruy González de Clavijo. La embajada a Tamorlán. Relato del viaje hasta Samarcanda y regreso (1403-1406)}

\section{Francisco López Estrada}

Arbor CLXXX, 711-712 (Marzo-Abril 2005), 515-535 pp.

El presente relato es una narración, puesta en boca de los embajadores enviados por Enrique III, rey de Castilla y León, que cuenta el viaje que hicieron hasta Samarcanda, capital del Imperio logrado por Tamorlán al cabo de su vida. Este viaje fue en parte por mar, hasta Trebisonda; luego, por tierra, hasta Samarcanda, y duró cerca de tres años. Los embajadores llegaron a su destino, pero poco después murió Tamorlán, y los enviados del rey castellano regresaron a Alcalá de Henares, donde informaron acerca de su cometido. La narración es uno de los primeros viajes que se cuenta como tal en la literatura española, y representa una obra lograda, situada en los comienzos del siglo $X V$, en lengua castellana; en lo histórico es un relato verídico del hecho acontecido.

\section{Propósito del estudio. Política exterior oriental de Enrique III}

El propósito de este artículo es mostrar el motivo y el contenido de un relato que se dice que escribió Ruy González de Clavijo, señor de la Corte de Enrique III, Rey de Castilla y León, sobre un viaje que hizo, con 
otros señores y el acompañamiento correspondiente, al Oriente próximo, especialmente hasta Samarcanda, la ciudad más representativa de aquella región, donde todos se entrevistaron con Tamorlán.

Enrique III, que reinó de 1390 a 1406, quiso establecer relaciones con este caudillo, que vivió una azarosa vida de 1386 a 1405 y que había logrado reunir un imperio muy extenso y poderoso en el Asia Media. A Tamorlán se le dieron también otros nombres, tales como Timur y Timurlenque (Lenk, el cojo, pues lo era), Tamurbeque, Timurbeque, y asimismo en latín y otros idiomas se le conoció como Tamerlan, el nombre común que se acomodó en Europa, tanto en los libros como oralmente entre mercaderes y viajeros. En España también se le ha llamado, sobre todo en formas escritas, Tamerlán, pero la forma castellana que más arraigó en la lengua histórica fue la de Tamorlán, y así lo llamaremos aquí.

Las relaciones concretas entre Tamorlán y Enrique III se encuentran entre las varias y diversas que emprendió el rey castellano en su política exterior en la parte oriental de Europa, y enlazaron su reino, de dimensiones geográficas relativamente pequeñas y situado en el occidente europeo, con el gran imperio que Tamorlán había formado en el Oriente Medio. Es un episodio que pertenece a los años finales de la vida del emperador oriental, y que, por otra parte, se relaciona con las normas de la conducta política del Rey castellano, al que no asustaba enviar a sus súbditos predilectos a viajes tan largos como este, para que le trajeran noticias ciertas de otras tierras. Esta embajada a Tamorlán fue la más importante, por la distancia a la que se hallaba y la nombradía y categoría social del personaje a la que iba dirigida.

Enrique III pretende en su reinado una política que busca la paz con los monarcas vecinos, excepto con los árabes que bordean su reino, considerados cemo enemigos seculares. De ahí la guerra contra Granada que el Rey prepara, con la aprobación de las clases sociales. Por otra parte, las cuestiones del Cisma ensombrecen la política religiosa; las relaciones con Portugal mejoran, y son buenas las conversaciones comerciales que se entablan con Flandes, Bretaña, Inglaterra y Alemania. Enrique III pretende solucionar con su voluntad de pacificación los problemas interiores, y en parte lo logra. En el exterior, África le atrae, la parte de las costas cercanas e incluso otras, más lejanas, las fronterizas con Asia. El Rey quiere conocer y saber de estas tierras, sobre todo de las orientales, de las que tenía informaciones confusas. Especialmente atiende a las noticias que son novedad: las relativas a la aparición de Tamorlán, con su asombrosa victoria lograda frente a los turcos. Poco años antes, en 1386, Turquía había derrotado en Nicópolis a un escogido ejército de caballería 
Ruy González de Clavijo. La embajada a Tamorlán...

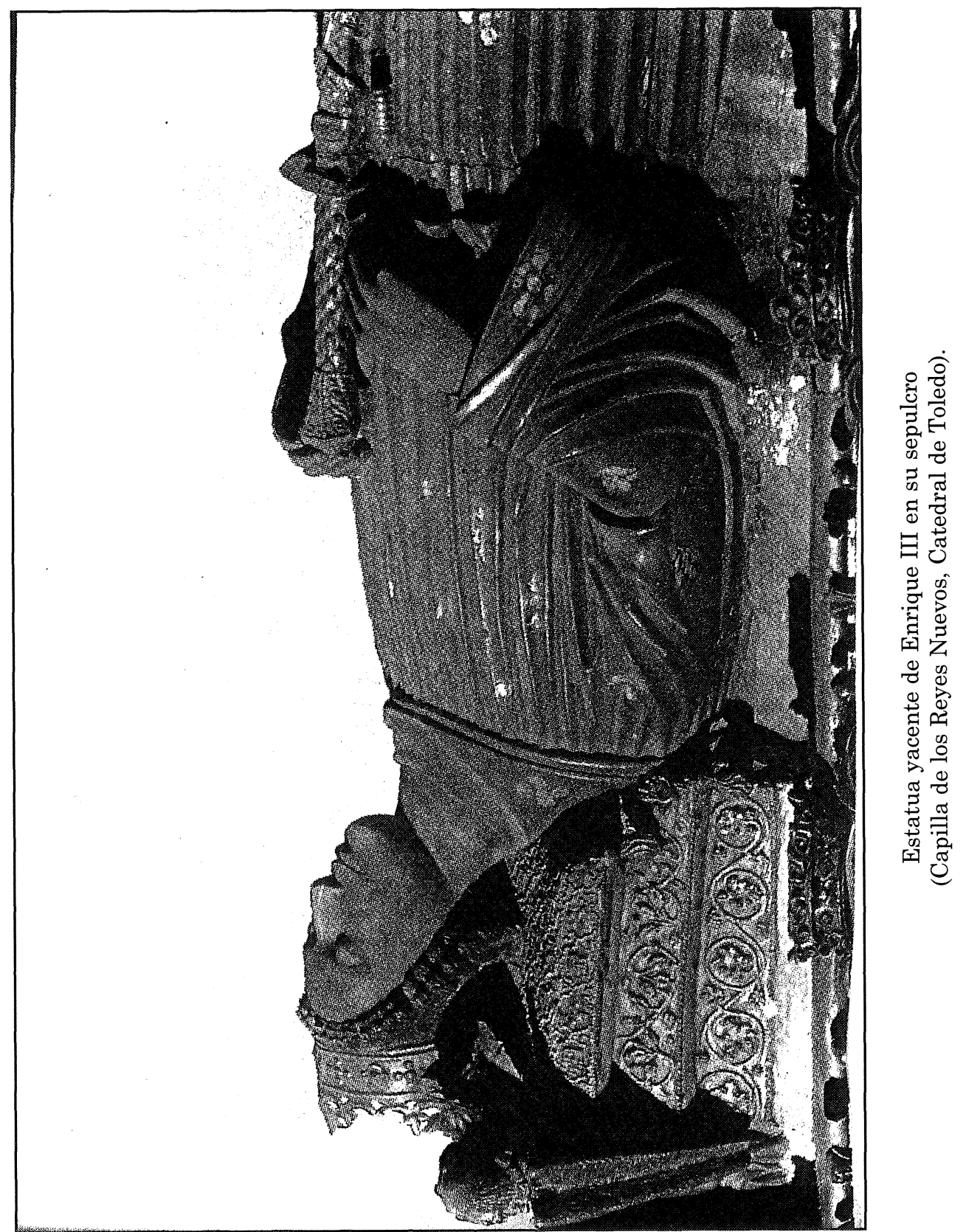


occidental europea, lo que representaba un peligro para la Europa oriental. Pero los turcos sufrieron en 1402 una derrota infligida por el caudillo Tamorlán. En un encuentro bélico inesperado, el caudillo oriental venció e hizo prisionero a Bayaceto en Ankara. Por ello, Enrique III quiso aprovechar la ocasión, y con voluntad pacificadora procuró entablar relaciones con la renovadora personalidad de Tamorlán, buscando los medios más idóneos para lograrlo.

\section{Los embajadores y su función amistosa}

Las historias que se refieren a estos hechos cuentan que Enrique III envió hacia el Oriente europeo a dos súbditos destacados de su Corte, Payo Gómez de Sotomayor y Hernán Sánchez de Palazuelos, para saber de aquellos lugares tan apartados de Castilla. Los enviados son llamados embajadores, término que se incorpora por entonces a los históricos, y pasa a formar parte del léxico de la diplomacia, que asegura un método de relaciones entre los reyes mediante sus enviados con unos fines determinados, como en este caso ${ }^{1}$. Los embajadores se encontraron en aquella batalla entre los turcos y las gentes de Tamorlán, en la que este venció, y Tamorlán trató a los castellanos con benignidad y cortesía. Cuando estos quisieron volver a las tierras castellanas, fue su voluntad que los acompañara un embajador propio, para trabar conocimiento y amistad con el rey Enrique III. Se trataba de un acto que en la diplomacia se llama "por procuración", de carácter itinerante. El embajador de Tamorlán era Muhammad Al-kazi, que en castellano se convirtió en Mohamad Alcagi, y vino acompañando a unas doncellas, que eran cristianas orientales (una, Angelina griega, fue ofrecida al Rey castellano con gran fortuna, pues se convirtió en dama de la corte).

No quiso Enrique III que quedara sin respuesta el señor oriental, y escogió a tres caballeros de su corte, junto con una compañía de gente preparada, para que acompañasen a Alcagi en el regreso a su tierra, y le ofreció también una donación adecuada, que sus embajadores presentaron a Tamorlán.

La elección de los embajadores fue acertada. El que actuó como cabeza de la nueva embajada fue Ruy González de Clavijo, caballero madrileño que formaba parte de la Corte, y estaba cerca del mismo monarca como su "camarero», o servidor de la Cámara real. Cuando realizó esta función, era de edad madura. De entre su actividad poética, queda de él testimonio de una poesía en lengua cancioneril, aunque puede que escri- 
Ruy González de Clavijo. La embajada a Tamorlán...

biera más. Casado con una dueña muy honrada, el viaje de Clavijo como embajador hasta Samarcanda fue su hazaña más notable. Se dijo de él que por ello siempre lo tendrían por noble en Castilla ${ }^{2}$.

Con él fue también fray Alonso Páez de Santa María, religioso de la orden de los Predicadores y maestro en Teología. Convenía que acompañase a los otros embajadores alguien entendido en religión, pues en el largo viaje tendrían ocasión de tratar con doctores en la ley islámica y buenos conocedores de esta religión, y, por tanto, era necesario alguien que supiese Teología en su versión cristiana, y probablemente también en la mahometana. Y además tenía que conocer otras lenguas distintas de la castellana, como es posible que supiera un fraile de esta orden y condiciones.

Otro de los embajadores fue un hombre de armas, Gómez de Salazar, al que se llama "guarda" del Rey, un oficio honorífico de palacio, que no pudo resistir la dureza del viaje y murió durante el mismo.

Acompañaban a estos unos catorce hombres que llevaban y cuidaban las ofrendas que Enrique III había elegido para Tamorlán; algunos serían escribanos de la Corte, hechos en otras ocasiones a estos quehaceres, que tomaban nota de lo que los embajadores veían y les decían que guardasen brevemente por escrito para elaborarlo después. Estos cuadernos y los recuerdos que los viajeros conservaban puede que fueran la base de la memoria sobre la que se redactó el escrito presentado al Rey por Clavijo. Este habría actuado como «autor» del mismo, y a su nombre se situó desde un principio la historia, que alcanza la categoría de literaria, la llamada Embajada a Tamorlán. De esta manera quedaba memoria de este hecho, iniciativa política del Rey en relación con los países lejanos y orientales con los que quería establecer contacto diplomático.

Los presentes con que Enrique III quiso obsequiar a Tamorlán fueron muy distintos de los que este había enviado al Rey castellano. No eran como aquellas damas orientales que Bayaceto había aprisionado y Tamorlán había entregado a Enrique III para mostrarle su benevolencia, sino objetos preciosos, como telas de escarlata, junto con tazas y otros objetos de plata, y también pájaros muy apreciados, señoriales, los halcones gerifaltes, cuyo traslado requeriría especial cuidado. En conjunto, dice el relato que Tamorlán «recibiólo y tomólo y hubo en ello gran placer».

\section{La «Embajada a Tamorlán», manuscritos y libros}

Lo más importante que resultó de esta relación establecida entre Tamorlán y Enrique III no fueron ni las damas ni los ricos regalos inter- 
cambiados, que se habían de perder finalmente con el tiempo, sino el relato que se escribió contando el viaje a Samarcanda y la vuelta a Castilla de los embajadores de Enrique III. Este relato nos ha llegado hasta hoy gracias a los manuscritos y después a la imprenta. El escrito de la relación, titulado generalmente Embajada a Tamorlán, se ha atribuido a Ruy González de Clavijo. No ha sido escrito en su redacción de una manera personal identificando al autor como tal, sino atribuyendo los hechos que se contaban a «los embajadores», que son la base del sujeto gramatical de la mayor parte de la redacción que cuenta el viaje y sus incidencias. Esta es la persona verbal que, salvo excepciones, sostiene la redacción del libro, atribuida siempre a Clavijo, se hiciera una lectura pública o personal del texto. De esta manera, el oyente o el lector participa en las vivencias de cuanto dicen y hacen los "embajadores", que es el equivalente humano del hecho colectivo de la embajada.

He escrito "salvo excepciones". Las excepciones a las referencias de "embajadores» como el sujeto dominante en la sintaxis de la Embaja$d a$ se encuentran citadas en un artículo de Patricie E. Mason sobre la sintaxis de la autoría del libro. Allí se recogen veinte veces el uso expresivo de la primera persona del singular del verbo, y diez y seis, de la de plural. Son leves variantes cuya interpretación no pide que sea otro autor que el mismo Clavijo ${ }^{3}$. Ya que los autores que se citan como los «embajadores» implícitos son tres, y uno muere en el viaje, quedan dos, el referido Clavijo, que es el que siempre se ha considerado como autor, y Fray Alonso Páez de Santa María, que no se ha mencionado como tal, aunque haya sus motivos para hacer alguna propuesta en este sentido. Esto hace que se entienda que Clavijo sea el narrador más plausible de los hechos del libro y el testigo caracterizador de lo que se dice en él. Además sabemos que Clavijo había sido escritor, y tenía condiciones y obra de poeta en el género cancioneril. Por su edad, que le supone experiencia en el uso de la escritura, puede considerársele también como autor de prosa castellana, según requiere el manuscrito, o como inspirador decisivo del mismo. De ahí que se le tenga el como autor de la obra.

La Embajada a Tamorlán se conserva en varios manuscritos y ediciones. Su referencia se encuentra en mi edición de Madrid del año $1999^{4}$. Allí doy noticias de los manuscritos de la Biblioteca Nacional de Madrid, y otro de la British Library de Londres, y otros de la Biblioteca Real de Palacio (incompleto) y de la Nacional de Madrid. Y de las ediciones de Madrid, 1582 y 1782; y luego siguen las modernas y las traducciones, que también enumero en mi estudio. En 2004 he publicado una edición de la 
Ruy González de Clavijo. La embajada a Tamorlán...

misma Embajada a Tamorlán en castellano moderno, en que ofrezco una versión actual de este libro ${ }^{5}$.

\section{Trayecto del viaje}

Según se dice en esta Embajada, los embajadores, sujeto verbal colectivo del relato, puestos en camino, primero siguen la ruta conocida, la del comercio, la propia de la mayor parte de los viajeros profesionales, en busca de Tamorlán. No interesa en principio el viaje como tal, sino llegar hasta donde se halle el inquieto Tamorlán para hacerle entrega del mensaje y de la donación que les había confiado su Rey. El viaje es seguido por los embajadores de una manera continua, y ellos lo cuentan en grado suficiente para que los lectores lo conozcan. El fin del mismo es Samarcanda, la ciudad que actúa como capital del reino de Tamorlán.

He dividido en diez partes el relato de la embajada: I, De Sanlúcar a Rodas; II, De Rodas a Constantinopla; III, La ciudad de Constantinopla; IV, De Pera a Trebisonda; V, De Trebisonda a Arzinga; VI, De Arzinga a Soltania; VII, De Soltania a Samarcanda; VIII, Samarcanda; IX, De Samarcanda a Trebisonda; X, De Trebisonda a Alcalá de Henares.

La narración del viaje comienza en la parte I con la llegada de los embajadores el 21 de mayo de 1403 al Puerto de Santa María. Al día siguiente embarcan los viajeros y su carga, los regalos y obsequios del Rey castellano, en una carraca, nave comercial, en la que hacen el viaje hasta Rodas. Con este fin, parten y pasan el Estrecho de Gibraltar siguiendo hasta Málaga, donde cargan mercancías en su nave; es ocasión de describir la Málaga entonces mora, muy poblada. Reanudan el viaje y por la costa llegan a Cataluña. Y después se dirigen hacia las Islas Baleares, donde el 5 de junio entran en el puerto de Ibiza. Allí los del navío vuelven a ocuparse de las mercancías, y entretanto los embajadores visitan al gobernador de Aragón. Describen la isla, y siguen después su trayecto y llegan a Córcega y Cerdeña, notando que van paralelos a la terrestre Roma; el 27 de junio llegan al puerto de Gaeta, que se describe, y también el paisaje y población e iglesias, y se cuentan hechos de Ladislao de Anjou. Una tormenta los azota dos días en el viaje hasta Sicilia, y después llegan a Mesina, y luego por entre las islas y alcanzan Rodas. Allí visitan al Teniente, que sustituye entonces al Gran Maestre, ausente. Permanecen en Rodas hasta el 30 de agosto, y no logran obtener noticias ciertas de dónde se halla Tamorlán. Esta parte de la navegación era utilizada por los que transitaban por el Mediterrá- 

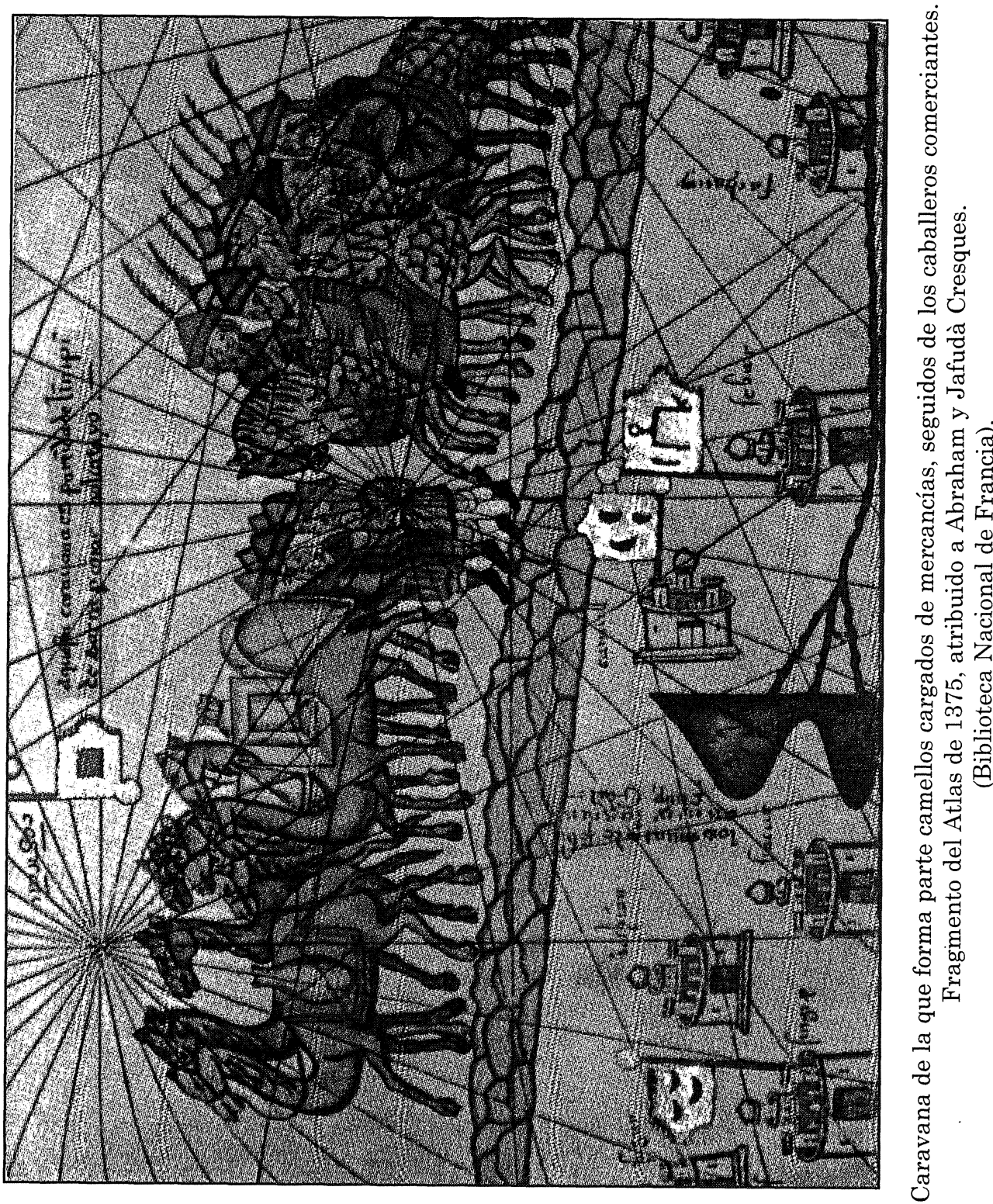
Ruy González de Clavijo. La embajada a Tamorlán...

neo, y los embajadores refieren los lugares y gentes más o menos conocidos por los viajeros.

En la parte II se describe el viaje desde Rodas hasta Constantinopla. Los embajadores fletan una nave hasta la isla de Chíos. Pasan cerca de las tierras turcas, peligrosas, y llegan hasta esta ciudad, donde han de permanecer hasta el 30 de septiembre. Fletan otra vez una pequeña nave, y ya están cerca de Constantinopla y navegan entre las islas y los estrechos. Contemplan el monte Athos, y describen los monasterios y los monjes griegos. Pasan las bocas de Romania, y el 28 de octubre llegan a Constantinopla, donde los recibe el Emperador con su familia.

En la parte III los embajadores visitan la ciudad, cuya grandeza decadente perciben, y describen en especial las grandes iglesias, como Santa Sofía, San Jorge y otras, y los monasterios, como el Pantocrator. Los guían el yerno del Emperador, el genovés micer Hilario, y otros servidores, que les muestran lo más notable, y aquellos admiran las numerosas reliquias religiosas.

En la parte IV empiezan por describir la vecina ciudad de Pera, centro comercial, donde han de permanecer hasta el 13 de noviembre, pues no encuentran nave que los lleve hasta Trebisonda. Por fin hallan una galeota que se atreve al viaje, y el 14 de ese mes embarcan hacia su destino, pero una tempestad los hace naufragar, aunque salvan lo que llevaban y consiguen volver no sin peligros hasta Pera. El Mar Negro no se puede navegar en el invierno, y han de permanecer en esta ciudad hasta que en la primavera, el 20 de marzo de 1404, reemprenden el viaje marítimo hasta Trebisonda, donde también visitan al emperador del lugar y se preparan para continuar el viaje por tierra hasta Samarcanda. Han de acomodar los obsequios reales a esta nueva circunstancia de transporte.

En la parte V están aún lejos de los dominios de Tamorlán, y en las primeras etapas les resulta difícil y costoso entenderse con los señores locales. Llegan a Arzinga y la describen con su mezcla de armenios y griegos. En esta parte el relato se refiere a Tamorlán, sus nombres y condición personal y a su enemigo Bayaceto y a su padre.

En la parte VI, los embajadores se trasladan desde Arzinga, de donde parten el 15 de mayo de 1404, hacia Soltania, a la que llegan el 16 de junio. Las jornadas son tranquilas porque, a medida que avanzan en su camino se van encontrando en lugares en que la autoridad de Tamorlán es efectiva. Van por tierras donde se cuenta que Noé comenzó la repoblación de los lugares terrestres después del Diluvio. Encuentran a un señor que dice que es católico y que los acoge muy bien. En Khoy acaba Armenia y comienza Persia. El 11 de junio llegan a Turis o Tabriz, ciu- 
dad que describen con pormenor, especialmente la mezquita y un hermoso palacio. Parten de allí el 20, y tienen que protegerse del calor que los acosa. Alcanzan Soltania el 26, y se ocupan de esta ciudad, sobre todo comercial, en la que se tratan muchas riquezas, como piedras preciosas que llegan de la China. Hallan al hijo de Tamorlán, con la locura que le causa en parte el prestigio de su padre.

En la parte VII se trata, por fin, de las jornadas que los conducen hasta Samarcanda, donde encuentran a Tamorlán. En esta parte están guiados y conducidos por emisarios del Señor, que se dispone a hacerles un digno recibimiento. Ya viajan en caballos del Señor. El 6 de julio llegan a Teherán, donde los reciben muy bien y los atiende un privado del Señor. El calor que padecen es mucho. Allí quedan enfermos algunos de los viajeros, que recogerán en el viaje de vuelta. El 17 de julio entran en Damonga (Dámghán), que era, acabada la Persia, tierra de la Media. Viajan por la noche para privarse del calor del día, que les duele mucho, hasta el punto de que muere Gómez de Salazar. Pasan a Horazania y, sufriendo grandes calores, van acercándose a su destino, y llegan a Anchoy; por lugares ya muy cultivados alcanzan Quix, y pronto alcanzan el objetivo del largo viaje: Samarcanda (Samaricante).

La parte VIII se dedica enteramente a la ciudad de Samarcanda. Primero llevan a los embajadores a un jardín en donde está el Señor, que con grandes saludos y reverencias los recibe como se dirá. Después describen las riquezas de Samarcanda, diciendo que es muy abastecida de comestibles y se tratan en ella mercancías de la China (Catay), India y Tartalia. En la ciudad se celebran grandes fiestas, a muchas de las cuales asisten los embajadores como invitados de honor, y las describen con la riqueza y lujo oriental que las caracteriza. En esto, Tamorlán cae enfermo y sus ministros despiden a los emisarios que estaban allí, entre otros a los castellanos. Sin obtener la apetecida respuesta de Tamorlán, que ellos desean, han de emprender el regreso.

El 18 de noviembre de 1404, guiados por un «chacatí» (caballero de procedencia tártara) con cuatro "albaláes»(documentos que les acreditan los medios de transporte) inician la vuelta a Castilla. Las partes IX y X cuentan el regreso, después de superar las dificultades en que hallan por la muerte de Tamorlán. Atraviesan las tierras de Horazania, Media y Persia. Durante el invierno de 1404 pasan mucho frío. Los problemas políticos de la sucesión del gobierno afectaron a los embajadores, pero por fin consiguen llegar a Trebisonda, donde comienza el regreso por la vía marítima.

$\mathrm{Y}$ la parte última, la $\mathrm{X}$ del relato, es breve, pues la vuelta por el mar entra ya en los medios comunes del viaje, y los embajadores se valen de 
Ruy González de Clavijo. La embajada a Tamorlán...

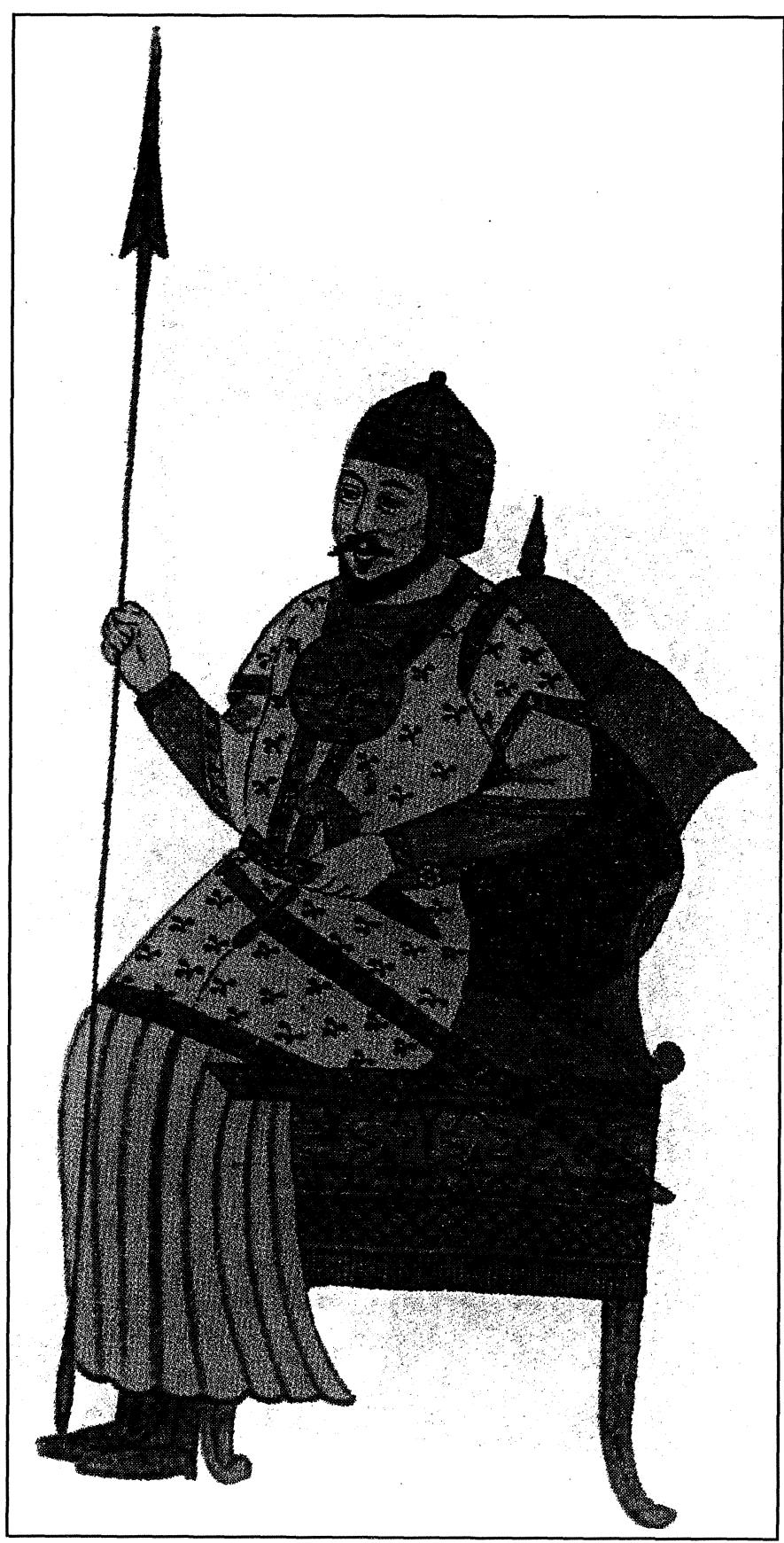

Tamorlán. Retrato cortesano tradicional. (Biblioteca Bodleyana). 
los recursos navieros conocidos. El 17 de septiembre de 1405 hallaron un barco que se iba a Pera, y lo tomaron, y el 22 de octubre llegaron allí. Después, en unas carracas de genoveses prosiguieron el viaje, y en medio de grandes tormentas, arribaron a Génova, que es la última ciudad que describen. Hicieron una gestión con el Papa Benedicto XIII y, por fin, tomaron tierra definitivamente en Sanlúcar. El 24 de marzo de 1406 terminaron el viaje en Alcalá de Henares, donde hallaron a su Rey Enrique III, que los había enviado a tan lejana embajada, y le dan cuenta de la misma. Y este es el contenido del relato Embajada a Tamorlán.

\section{El imperio reunido por Tamorlán y la variedad de sus súbditos}

Los embajadores sólo tienen ocasión de testimoniar cómo era el imperio reunido por Tamorlán en su periodo final, pues, tras contar las riquezas de la ciudad de Samarcanda, el emperador oriental prepara la marcha para la invasión de China, y en esta empresa murió. El periodo último de su gobierno, que es el que han conocido y cuentan los embajadores, es de una gran brillantez. Tamorlán fue a Samarcanda para comprobar la que era como la capital del imperio que había logrado reunir ${ }^{6}$. Los embajadores castellanos lo encontraron allí, y él los trata como un gran señor en los palacios y jardines de Samarcanda.

Hay una especie de identificación entre la capital y el gran señor que perciben los embajadores en cuanto llegan a la gran ciudad y permanecen en ella. La voluntad de engrandecer la ciudad está declarada de una manera patente, y los medios de que Tamorlán ${ }^{7}$ dispone no tienen límites humanos. He aquí cómo los embajadores interpretan que esto ha acontecido: "...el Señor avía gran voluntad de enoblecer esta ciudat, ca en cuantas tierras él fue e conquistó, de tantas fizo levar gente que poblasen en esta ciudat e en su tierra, señaladamente de maestros de todas artes». Es decir, que no reconoce origen ni lugar, sino que dominen la maestría en su arte. Y sigue escribiendo: «De Damasco levó todos los maestros que pudo aver, así de paños de seda de muchas maneras, como los que fazen arcos en que ellos tiran, e armeros, e los que labran el vidrio e barro, que los avía allí los mejores del mundo» ${ }^{8}$. Esta era la finalidad: obtener los mejores gentes que trabajen en las más diversas materias del mundo, no importa en lo que sea. Y menciona después turcos, árabes de distintas naciones, cristianos armenios, griegos católicos, nestorinos y jacobinos. Y usa su expresión favorita: «avía tantos, que era maravilla» ${ }^{9}$. 
Ruy González de Clavijo. La embajada a Tamorlán...

Y no sólo había reunido los mejores obreros del mundo a su alcance, sino que Samarcanda era la ciudad mejor abastecida en todo y en lo de mayor precio: «E otrosí esta ciudat es muy abastada de muchas mercadurías que en ella vienen de muchas partes» ${ }^{10}$. Y se cita la procedencia de Rusia, Tartalia, el Catay y la India, con los elogios consiguientes. Los embajadores proceden de Europa, de su occidente. y estas son las partes orientales de la misma que se les manifiestan como creadoras de una riqueza sin igual, que ellos ponen de relieve y describen.

La variedad de súbditos, aunque fuesen reunidos y forzados por las sucesivas guerras con que Tamorlán los había juntado, es una manifestación que los embajadores perciben en sus viajes a través del imperio del Señor, al que visitan en nombre de su Rey. Y ellos recogen su última manifestación, la más demostrativa de un poder que está en su más alto grado y, al mismo tiempo, en su término.

\section{Monumentos religiosos cristianos y mahometanos. Su apreciación e interpretación}

Los embajadores tienen ocasión de ver monumentos de las distintas religiones en los lugares por los que pasan y de observar el culto que se celebra en los mismos. Los que pertenecen a la católica son los propios de sus creencias, y los mencionan según su consideración personal y colectiva. El latín es la lengua de la iglesia, y uno de los embajadores, fray Alfonso Páez, de la orden de los Predicadores, pertenece a ella; es de suponer que los otros también entienden el latín hasta un cierto grado. No hay que olvidar que conocen un dicho que les puede valer: «Con latín, rocín y florín, andarás el mundo hasta el fin». De ahí que la Embajada sea un libro en el que se mencionan iglesias y también monumentos religiosos, siempre que por algún motivo hayan llamado la atención de los viajeros.Y en los testimonios del comienzo de la narración abundan los católicos por la naturaleza del trayecto. La devoción se aprecia, por ejemplo, en Gaeta: «En esta ciudat ha una iglesia muy devota, en que han las gentes muy gran devoçón; y es llamada Santa María el Anunciada. E delante está otra iglesia devota, que es llamada sant Antón. E encima d'esta iglesia de santa María, está un fermoso monesterio de sant Francisco» ${ }^{11}$. He aquí que la devoción se reúne con la apreciación de la hermosura del monasterio y la devoción que causa el grupo de edificios. Sin embargo, hay pocas ocasiones en que los embajadores tienen ocasión de manifestarlo, pues pronto se alejan de lugares como este. A medida 
que entran en el Oriente, la contemplación de los monumentos de orden católico disminuye, como es lógico.

En Constantinopla tienen ocasión de describir monumentos e iglesias de gran relieve; algunas de ellas se hallan en estado ruinoso. Los datos que se recogen en estos casos son ya propiamente arqueológicos; el efecto de su contemplación en los embajadores no es de religiosidad, sino de "extrañeza». Pondré como ejemplo el caso de la primera iglesia de la gran ciudad que ellos visitan y describen: «La primera cosa que les fueron mostrar fue una iglesia de sant Johan Bautista, que llaman sant Juan de la Piedra, la cual iglesia está cerca del palacio del Emperador. E luego, encima de la su entrada primera d'esta iglesia, estava de una figura de sant Juan muy rica e muy debuxada, de obra de musica (mosaico). E junto con esta puerta, estava un chapitel alto, armado sobre cuatro otros; e so él pasan para entrar al cuerpo de la iglesia. E el cielo d'este chapitel e las piedras d'él es todo imaginado de imágenes e figuras muy fermosas, de obras de musica. La cual obra de musica son de unos pedaçuelos muy pequeños, que son d'ellos dorados de fin oro, e d'ellos de ezmalte e azul e blanco e verde e colorado e de obras muchas colores (...); así que esta obra paresce extraña de ver» ${ }^{12}$. He aquí una primera descripción de la obra de mosaico, que los embajadores contemplan por vez primera (o al menos así la describen); declaran su "extrañeza» y la ponen de manifiesto con una evidente apreciación de una realidad artística nueva y asombrosa para ellos. Y, con igual aprecio por una realidad artística que les es ajena, recorren los numerosos monumentos de Constantinopla, y aprecian sobre todo su decadencia: "Otrosí por esta ciudat de Costantinopla ay muy grandes edeficios de casas e de eglesias e de monesterios, que es lo más d'ello todo caído. E bien paresce que en otro tiempo, cuando esta ciudat estava en su virtud, que era de las nobl's ciudades del mundo. E dizen que oy en día ha en esta ciudat bien tres tres mil iglesias, entre grandes e pequeñas» ${ }^{13}$.

Como los viajeros están meses en Constantinopla, les da también tiempo de ver los monumentos civiles. Al no mezclarse cuestiones religiosas, tienen el juicio más libre al contemplarlos. Este es el caso del Torneamiento (o sea el Hipódromo), en que los embajadores enjuician el monumento (o construcción civil) según su uso, que es actual para ellos, aunque fuese en su origen muy distinto, lo que da originalidad a su aprecio. Dice el texto: «Este día les fueron mostrar un campo que está en la ciudat que es llamado el Torneamiento, onde solían justar e tornear, el cual es cerrado de mármol's blancos, e tan gruesos cuantos tres o más podrían abraçar; e tan altos como dos lanças de armas o más. Los cuales 
mármoles fueron puestos por compás, uno ante otro alderredor(...).Todo lo qual era fecho a efecto de que sobre estos dichos mármoles acostumbravan a estar las dueñas e doncellas e gentil mugeres cuando miravan las justas e torneos que allí se fazían» ${ }^{14}$. He aquí el aprovechamiento social que obtiene el monumento de la Antigüedad en la época de los embajadores, y que tienen ocasión de testimoniar. Los mármoles ${ }^{15}$, que acaso son las estatuas que ven, sin que tengan que ver para ellos con un criterio estético ajeno, se mezclan con las justas y torneos del tiempo medieval, que es el propio de los embajadores viajeros, y que para ellos representa su realidad artística, lo mismo que para las dueñas y doncellas.

En Pera tienen ocasión de admirar dos monasterios religiosos, el de san Pablo y el de San Francisco ${ }^{16}$. Y ya se les acaba la contemplación de la catolicidad. En Trebisonda describen el culto armenio, ya diferente del católico, y luego, por el trayecto terrestre penetran en el mahometismo, religión ajena para ellos, pero cuya gracia arquitectónica reconocen; también notan la diferencia de vestimenta como signo de hallarse rodeados de otra cultura, sobre todo en las mujeres. Cuando pasan por Tabriz, dicen de la ciudad: «E por la dicha ciudad ha muchas rúas e calles muy ordenadas, ca entre estas calles e rúas venden muchas cosas, e están oficiales de muchas maneras, muy bien ordenadas.(...)» $\mathrm{Y}$ sigue la descripción: «E es ciudat de gran bollicio e de muchas mercadorías. E en un lugar d'estas alcaicerías están unos omnes que venden muchas oluras e afaites para las mujeres, e ellas mismas vienen allí a lo comprar, e se afeitan e untan con aquellas cosas. E vienen todas cubiertas con sávanas blancas, e ante los ojos, unas redes de sedas prietas de cabellos. Así van cerradas, que no las pueden conoscer». Y esta descripción de la ciudad y del mercado femenino enlaza con la de la hermosura de la arquitectura, que los viajeros resaltan por su colorido, y se manifiesta la belleza apreciada alrededor de las mezquitas: «En esta ciudat ay muy grandes edificios de casas e mezquitas, fechas de maravillosa obra de azulejos e de losas e de azul e de oro e obra de gesería, e vidrieras muy fermosas e muchas» ${ }^{17}$. Pero antes los viajeros, que manifiestan su capacidad de apreciar esta hermosura, notaron también los rasgos contrarios: « $\mathrm{E}$ domingo siguiente fueron dormir a una aldea que ha nombre Mular Chemon, que quiere decir el aldea de los locos. E los que en esta aldea bivían eran moros como hermitaños que han nombre caxistres, e mucha gente de moros vivían allí e venían a ellos como en romería; e muchos dolientes allí guarescen; e entre ellos avía un mayoral que le catavan mucha onra e dezían que era santo. (...) E estos hermitaños eran gentes que les fazían muchas limosnas las gentes, e el su mayoral era señor d'esta al- 


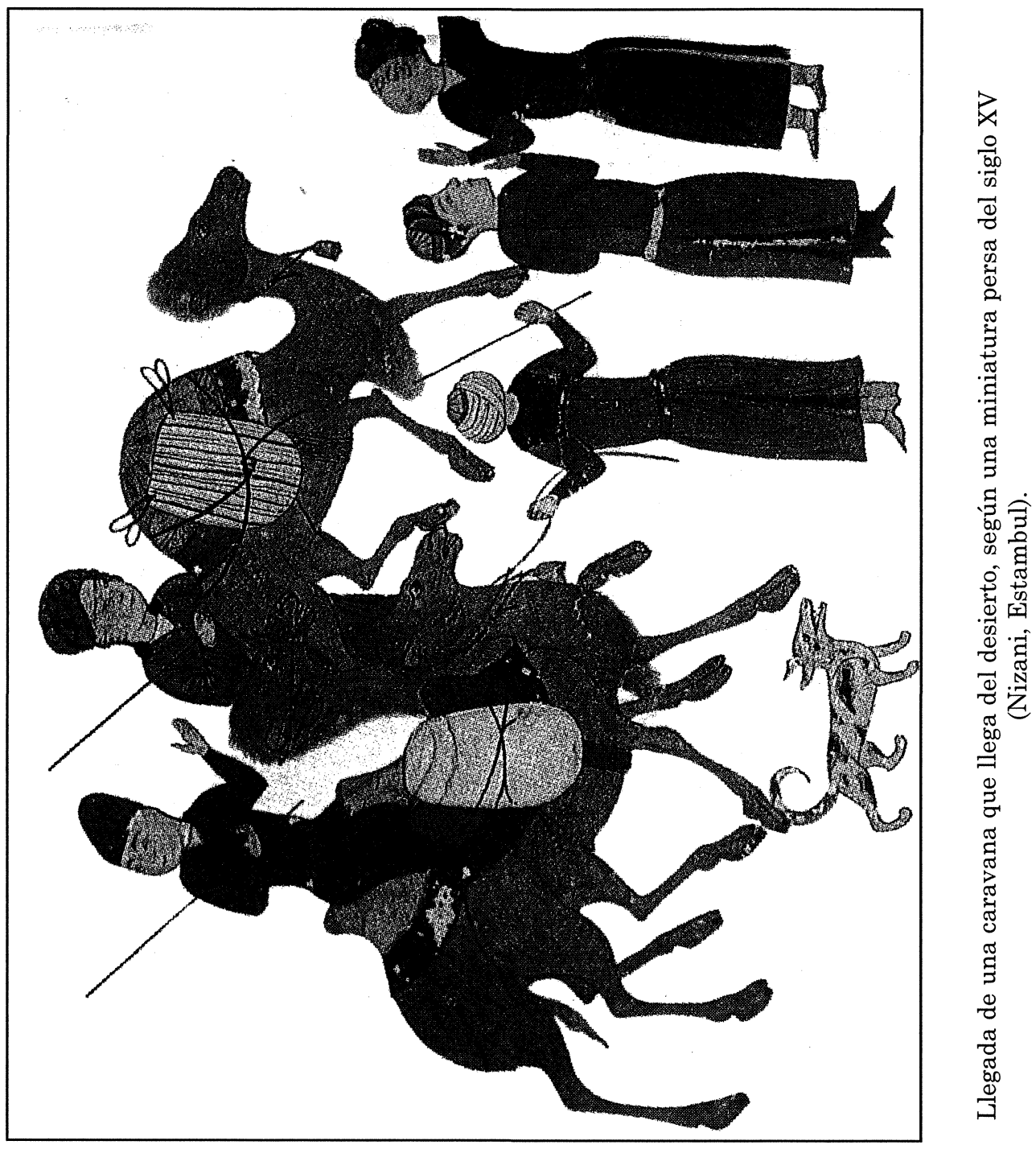


Ruy González de Clavijo. La embajada a Tamorlán...

dea. E los que d'ellos querían ser religiosos e que las gentes los ayan por santos, rápanse las barbas e las cabeças e desnúdanse e andan desnudos por las calles, e al sol e al frío; e andan comiendo por las calles e vístense de los paños más rotos, e andan cantando de día e de noche con panderos» ${ }^{18}$.

El contraste está logrado. Los viajeros mantienen la capacidad de notar la belleza de las mezquitas, cuidadosamente construidas, y al mismo tiempo el espectáculo de los que buscan una santidad elemental, lograda con la desnudez y la pobreza manifiesta. Todo lo contemplan mientras dura su viaje hasta llegar a la gran ciudad, Samarcanda. No callan ni lo bueno ni lo malo, y por eso la Embajada a Tamorlán es un relato testimonial de primer orden, en que los «los embajadores», así en plural, manifiestan su apreciación de la diversidad del viaje, aunque en alguna ocasión aparezca su singular personalidad.

No solamente el narrador pone su atención en los monumentos y en las diferentes gentes que encontró, sino también en los animales que le llamaron la atención, diferentes de los que conocía. Entre las novedades zoológicas, es muy notable la aparición de una jirafa (a la que llaman en este texto jornusa), que el Sultán de Babilonia envía a Tamorlán y que se describe minuciosamente (pp. 197-199 de la ed. medieval, 1999, y pp. 136-7 de la moderna, 2004). Y también son notables las menciones de los elefantes domados (marfiles), que juegan entre el público (citadas, por ejemplo, en las pp. 293-296 de la ed. medieval, 1999, y pp. 219-221, de la ed. moderna, 2004), con la descripción de las habilidades que logran sus domadores.

\section{Otro testimonio de la «Embajada» en el siglo XVII}

Además del texto medieval y de los otros citados, otro testimonio confirma que la Embajada se conoció, y es una cita del siglo XVII. Esta mención se encuentra en un libro escrito por el Maestro Gil González Dávila, impreso cuidadosamente en Madrid por Francisco Martínez, y dedicado a Felipe IV el año $1688^{19}$. Se trata de una historia de Enrique III, hecha por este historiador. En la mención de los hechos del año 1403, el cap. LXXII lleva este título «De los Embaxadores que el Rey don Henrique embió al Gran Tamorlán y a Bayaceto, gran señor de los turcos». González Dávila cita el encuentro entre Bayaceto y Tamorlán con exageración, pues dice que en él se juntaron «dos millones de hombres, que fue el mayor poner que se sabe por historias» ${ }^{20}$. Estas cifras señalan versiones que no son propia- 
mente históricas, y se mencionan con otros sucesos y también se mezclan con la historia verídica de Sánchez de Palazuelos y Gómez de Sotomayor, que fueron los primeros embajadores de Enrique III a Tamorlán. González Dávila menciona también la segunda embajada, la que se estudia en este artículo, y da el nombre de los tres embajadores, Clavijo, fray Alonso Páez y Gómez de Salazar, señalando que el primero es el autor del relato del mismo: «Escriuió vn itinerario asaz curioso Rui González de Clavijo» ${ }^{21}$.Y hace un resumen acertado de su contenido real: «...que lleuaron cosas marauillosas, que vieron fortunas y trabajos, que pasaron diferencias de climas, leyes, costumbres y condiciones de gentes ${ }^{22}$. Y escribe el principio del relato señalándolo casi con las mismas palabras que Clavijo: « En el nombre de Dios, en cuyo poder son todas las cosas, e a honor de la Virgen Santíssima María, su Madre, començé a escrivir desde el día en que los embajadores llegaron al Puerto de Santa María....23. A continuación sigue un resumen de cerca de tres páginas que testimonian suficientemente que González Dávila disponía de un texto completo, como el publicado en 1582 por Argote de Molina o algún manuscrito. Acaba el relato diciendo que los embajadores volvieron a Alcalá de Henares, y resume así: «Dando por menor mui larga cuenta de todo, causó admiración, siendo esto el más sustancial efeto que resultó de tan remoto viaje, quedando los Embaxadores en grande veneración con los demás vassallos por lo mucho que auían visto, padecido y vencido en tierras bárbaras» ${ }^{24}$. Termina la mención de los viajeros con el epitafio de Clavijo; «fue sepultado en la dicha Capilla Mayor [de San Francisco de Madrid] en un túmulo de alabastro suntuoso y ricamente labrado con su bulto, y con letras en torno dél que decían: «Aquí yace el honrado cavallero Rvi Gonçález de Clavijo, que Dios perdone, Camarero de los Reyes don Henrique, de buena memoria, e del rey don Iuan, su fijo, al qual el dicho señor Rey ovo enviado por su Embaxador al Tamorlán, e finó a dos días de Abril, Año M.CCCC.XII.. ${ }^{25}$. Hay noticias de que fue cambiado por otro de la reina doña Juana, mujer de Enrique IV. También estos datos sobre Clavijo se pueden completar en mi edición de 1943 (pp. LXV-LXXXIV) y otras. Estas noticias han completado lo que sabíamos sobre los segundos embajadores enviados a Tamorlán, y confirman la Embajada a Tamorlán ${ }^{26}$, y a Clavijo, como su autor, según es tradición.

\section{Testimonios actuales de la «Embajada a Tamorlán»}

Los recientes estudios sobre el libro de Clavijo han aportado más datos sobre el viaje. He tenido ocasión de reunir noticias complementarias 


\section{Ruy González de Clavijo. La embajada a Tamorlán...}

sobre las menciones de Tamorlán en la literatura española, y las he agrupado en distintos artículos. Primero me refiero a las que se encuentran en varios textos del siglo XV ${ }^{27}$. Luego, en los de los Siglos de Oro ${ }^{28}$. Después, estudio las referencias que se hacen en otros textos relativos a Blanco White (1884-1885) ${ }^{29}$. También se trata del libro de Clavijo en la obra de Carlos Montojo Jiménez La diplomacia castellana bajo Enrique III. Estudio preliminar de la Embajada de Ruy González de Clavijo a la corte de Tamerlán, en un prólogo publicado en el mismo ${ }^{30}$. Estas son las últimas aportaciones al libro de Ruy González de Clavijo, uno de los que mejor manifiesta el género de los libros de viajes en el último siglo de la literatura medieval española, con el relato del itinerario verídico a Samarcanda, realizado por los embajadores de Enrique III enviados ante el Gran Tamorlán.

\section{Notas}

1 Véase para esta gestión el fundamental libro de OCHOA BRUn, Miguel Ángel, Historia de la Diplomacia Española, Madrid, Ministerio de Asuntos Exteriores, I, 1990, pp. 229-245.

2 Véase una biografía en EzquerRa ABADÍA, Ramón, Ruy González de Clavijo, viajero de Asia Central, Madrid, Ayuntamiento, 1974. Pueden completarse las referencias con los datos de mi edición primera de la Embajada a Tamorlán, Madrid, CSIC, Instituto Nicolás Antonio, 1943.

${ }^{3}$ Patrice E. MASON, «The Embajada a Tamorlán: Self-reference and the Question of Authorship", Neophilologus, 78, 1994, pp.78-87. En mi obra Libros de viajeros hispánicos medievales, Madrid, Colección Arcadia de las Letras, Editorial Laberinto, 2003, puede hallarse la situación de la Embajada a Tamorlán en el conjunto de los libros de viajes.

4 GonZÁlez De ClaviJo, Ruy, Embajada a Tamorlán, Madrid, Clásicos Castalia, edición, introducción y notas de Francisco López Estrada, 1999, pp. 53-57.

5 González de Clavijo, Ruy, Embajada a Tamorlán, Madrid, Editorial Castalia, versión actual de Francisco López Estrada, 2004.

${ }^{6}$ De aquí en adelante mencionaré los textos de la edición medieval, o sea la de Madrid, Clásicos Castalia, 1999, seguida de la página donde se halla la cita.

7 Embajada a Tamorlán, 1999, p.312.

8 La misma página.

9 Embajada a Tamorlán, 1999, p. 313. Véase el estudio de la palabra maravilla en los libros de viajes, en Miguel Ángel PÉREz PrIEGo, «Maravillas en los libros de viajes medievales», Literatura de viajes, $n^{\circ} 7$ de «Compás de Letras», Servicio de Publicaciones de la Universidad Complutense, diciembre 1995, pp. 65-78, donde se menciona el uso de la palabra en el libro de Clavijo.

10 Embajada a Tamorlán, 1999, p. 313.

11 Embajada a Tamorlán, 1999, p. 87.

12 Embajada a Tamorlán, 1999, pp. 117-118.

13 Embajada a Tamorlán, 1999, p. 143. 


\section{Francisco López Estrada}

14 Embajada a Tamorlán, 1999, pp. 125-126.

15 Embajada a Tamorlán, 1999, pp. 147-148.

16 Embajada a Tamorlán, 1999, pp. 147-148.

17 Embajada a Tamorlán, 1999, p. 200.

18 Embajada a Tamorlán, 1999, pp. 188-189.

19 Gil González Dávila, Historia de la vida y hechos del rey don Henrique tercero de Castilla..., Francisco Martínez, 1688. La cita se encuentra en las pp. 173-178.

20 Idem, p. 173.

21 Idem, p. 175.

22 Idem, p. 175.

23 Idem, p, 176.

24 Idem, p. 178.

25 Joseph Antonio de BAENA, Hijos de Madrid, ilustres en santidad, dignidades, armas, ciencias y artes, Diccionario Histórico..., Madrid, MDCCXCI, tomo IV, pp. 302.

${ }^{26}$ Para esta parte final, véase Agustín Millares CARLo, Tres estudios bibliográficos, (III), " El Cronista Gil González Dávila y sus obras», Maracaibo, Universidad de Zulia, 1961. La referencia bibliográfica, en la p. 160.

27 Studia in honorem Germán Orduna, Leonardo FunEs y José Luis MouRE, (editores), Universidad de Alcalá, 2001, pp. 369-374.

${ }_{28}$ Estudios de Filología y Retórica en Homenaje a Luisa López Grigera, Edición coordinada por E. ARTAZA, J. DuRÁn, C. Isasi, J. LaWAND, V. Pineda y F. Plata, Universidad de Deusto, Bilbao, 2000, pp. 303-310.

29 «La revisión de José María Blanco White acerca de la Embajada a Tamorlán, publicada en las Variedades o Mensajero de Londres, (1824-1825)", Mélanges Luce LópezBaralt, I, , Ed. Prof. Abdeljelil Temimi, Zaghouan, 2001, pp. 393-401.

30 El estudio mío, prólogo, se titula «La embajada a Tamorlán de Clavijo y el estudio de...», pp. 9-14.

\section{Bibliografía}

Ezquerra AbadíA, Ramón, Ruy González de Clavijo, viajero por el Asia Central, Madrid, Ayuntamiento, 1974.

Gonzalo De ClaviJo, Ruy, Embajada a Tamorlán, Madrid, CSIC, Instituto Nicolás Antonio, 1943.

GonZÁleZ DE ClaviJo Ruy, Embajada a Tamorlán, edición, introducción y notas de Francisco López Estrada, Madrid, Castalia, 1999. Texto medieval y estudio previo.

GonZÁleZ DE ClAVIJo, Ruy, Embajada a Tamorlán, versión en castellano actual y edición de Francisco López Estrada, Madrid, Castalia, 2004.

La route de Samarcande au temps de Tamerlan. Relation du voyage de l'ambassade de Castille à la cour de Timour Beg, par Ruy González de Clavijo, 1403-1406, Paris, Imprimérie National éditions, 1990. Traducción francesa de la Embajada en texto literario del libro medieval castellano. Amplio prólogo, notas y abundante bibliografía.

LóPez EsTRADA, Francisco, «Procedimientos narrativos en la Embajada a Tamorlán», El Crotalón, I, (1984), pp. 27-47.

Misión diplomática de Castilla a Samarcanda, edición de Leoncio Cabrero, traducción al ruso de Claudio Klotchkof, Madrid, Ediciones de Cultura Hispánica, 2000. 


\section{Ruy González de Clavijo. La embajada a Tamorlán...}

MontoJo JimÉnEz, Carlos, La diplomacia castellana de Enrique III. Estudio preliminar de la embajada de Ruy González de Clavijo a la corte de Tamerlán, Madrid Escuela Diplomática, 2004.

OCHOA BRUn, Miguel Ángel, Historia de la Diplomacia española, I, Madrid, Ministerio de Asuntos Exteriores, 1990.

TAYLOR, Barry, "Los libros de viajes de la Edad Media Hispana: bibliografía y recepción", Actas IV Congresso da Associação Hispánica de Literatura Medieval, I, Lisboa, Cosmos, 1991, pp. 57-70. 